\title{
Research on the Upgrading Path of Regional Equipment Manufacturing Industry
}

\author{
Li Yue *1, Qian Keyan², Sun Xiaoyan ${ }^{3}$ \\ ${ }^{1}$ School of Economics and Management, Harbin University of Science and Technology, Harbin, China \\ ${ }^{2}$ School of Economics and Management, Harbin University of Science and Technology, Harbin, China \\ ${ }^{3}$ School of Economics and Management, Harbin University of Science and Technology, Harbin, China
}

\begin{abstract}
Constructing the upgrading path of regional equipment manufacturing industry based on innovation network is of great significance for solving the transformation and upgrading problems of regional equipment manufacturing industry in China, further catching up with the development level of equipment manufacturing industry in developed countries, and alleviating the regional gap. Based on literature analysis and industrial upgrading theory, this paper puts forward the basic principles and general ideas of upgrading path design of regional equipment manufacturing industry, focusing on designing industrial upgrading path based on key common technologies, industrial upgrading path based on industrial chain optimization and industrial upgrading path based on innovation platform, and finally puts forward corresponding countermeasures and suggestions.
\end{abstract}

\section{INTRODUCTION}

As the backbone of the modern industrial system, the equipment manufacturing industry is a high-employment and high value-added industry, which is closely related to other industries and has a strong driving force. It is of great strategic significance to take the equipment manufacturing industry as a breakthrough in the transformation from a "big manufacturing country" to a "powerful manufacturing country". With the implementation of China's innovationdriven strategy and the promotion of "Made in China 2025", the development of equipment manufacturing industry presents a new trend of networking and intelligence. Although China's equipment manufacturing industry has made some achievements in recent years, there are still some problems, such as over-reliance on input of production factors, lack of independent design capability and key core technologies, and weak supporting capacity. Under this background, how to realize technology productization, industrial clustering, complete sets of equipment and supporting localization in order to comprehensively promote the innovation and upgrading of regional equipment manufacturing industry has become an urgent major issue.

Foreign scholars have defined industrial upgrading from different levels and perspectives. Porter (1990) defined industrial upgrading from the macro level as making capital and technology intensive industries obtain rich resources through the factor transfer of enterprises within the industry, so as to obtain competitive advantages and obtain greater profit advantages by relying on resource advantages [1]. Gereffi (1999) thinks that industrial upgrading is a process from labor-intensive industry to capital or technology intensive industry for enterprises [2].
According to the research on manufacturing enterprises, Poon (2004) concluded that industrial upgrading is the transformation process of economic role of manufacturing enterprises from producing labor-intensive low-value products to producing capital or technology intensive highvalue products [3].

While exploring theoretical research, scholars at home and abroad are also actively exploring industrial upgrading paths that can guide practice. Masami (2013) studied the cases of product and process innovation, technology and management practice investment promoting industrial upgrading in five countries [4]; Li Weiqing (2013) studied the upgrading path of information industry based on technological innovation [5]; As a matter of fact, domestic studies mostly build upgrading paths from the value chain theory; Zeng Gui (2011) designed seven optional upgrading paths for China's processing trade industry, including inter chain upgrading, intra chain upgrading, regional upgrading and main body upgrading, enterprise transformation, trade mode transformation and material procurement upgrading [6]; Tu Yingqing (2011) put forward the upgrading path based on embedding the global value chain, and realized the transformation and upgrading of China's automobile industry through joint venture, selfconstruction and development of strategic emerging industries [7]; Qian Fangming (2013) constructed the national value chain in the Yangtze River Delta region, and discussed the main upgrading paths of traditional manufacturing industries in the Yangtze River Delta region-the upgrading paths driven by leading enterprises, cluster enterprises and professional markets [8]; Wang Haijie (2014) built a regional value chain based on the regional "resources-environment" dimension, and realized industrial upgrading in underdeveloped areas by relying on

*Corresponding author: lykusha@163.com 
the horizontal and vertical joint action of characteristic industries [9].

To sum up, domestic and foreign scholars have made some achievements in the research of industrial upgrading, but there are still some shortcomings in guiding the upgrading of China's regional equipment manufacturing industry. Although some scholars have discussed the upgrading path of equipment manufacturing industry, they haven't systematically given the specific industrial upgrading path design method, which is insufficient for guiding the upgrading and development practice of equipment manufacturing industry. In order to solve the problems of low added value and lagging overall development of regional equipment manufacturing industry, aiming at the actual needs of regional equipment manufacturing industry development, this paper designs the upgrading path of regional equipment manufacturing industry based on innovation network on the basis of reference of relevant theoretical research, which is conducive to enhancing the core competitiveness of regional equipment manufacturing industry, building a new pattern of industrial synergy and symbiosis, and has great practical significance for breaking through the bottleneck of regional equipment manufacturing industry development and realizing innovation, upgrading and sustainable development.

\section{THE PROCESS AND LAW OF UPGRADING REGIONAL EQUIPMENT MANUFACTURING INDUSTRY}

This paper argues that the upgrading of regional equipment manufacturing industry is a process of realizing the transformation of equipment manufacturing industry from low level, low added value and low technology to high level, high added value and high technology under certain regional environment constraints. under certain regional environmental constraints, by improving the production equipment level and efficiency of equipment manufacturing industry, mining, integrating and utilizing innovative resources, enhancing independent innovation ability, further optimizing the division of labor and cooperation from conception to sales.

\section{A. The process of regional equipment manufacturing upgrading}

The upgrading process of regional equipment manufacturing industry can be divided into three stages: factor upgrading, value chain upgrading and industrial structure upgrading. In the stage of factor upgrading, the network scale centered on core manufacturing enterprises is constantly expanding, and the increase of network relations leads to the improvement of innovation resource integration ability, and the increase of technological innovation activities devoted to the improvement of product added value and production efficiency. When low-level product and process innovation can no longer bring new value to customers, it will enter the stage of value chain upgrading, and it is necessary to optimize and integrate the value chain of equipment manufacturing industry, and enhancing the added value of industry from the production links and non-technical links other than production. The upgrading of industrial structure gradually increases the proportion of high-tech sub industries in the equipment manufacturing industry and optimize the backward traditional equipment industry in the penetration of innovation factor flow and supporting industry optimization.

\section{B. The law of upgrading regional equipment manufacturing industry}

The upgrading of regional equipment manufacturing industry is the superposition of upgrading links at different levels. Three upgrading processes are progressive and mutually advancing, among which the upgrading of internal structure of equipment manufacturing industry has a relatively long period of time, which also needs to be paved by the upgrading of elements and value chains.

Technological innovation is the internal motive force of upgrading regional equipment manufacturing industry. Technological innovation has a long-term and far-reaching impact on the upgrading of regional equipment manufacturing industry. Technology supports the development of equipment manufacturing industry. Advanced manufacturing technology means added value of high technology, and the introduction of new technology has changed the market competition pattern and focus. However, the high risk and high investment in innovation and $R \& D$ make the manufacturing enterprises draw back and choose to imitate innovation.

Therefore, it is still the large-scale manufacturing core enterprises that master the core technology. During the upgrading process of regional equipment manufacturing industry, the number of innovation resources, innovation subjects and relationship connections increased rapidly at first and then slowly reached zero. In the process of upgrading, the innovation subject will enter or withdraw from the innovation network due to the demand of industrial development, resulting in the replacement of innovation resources and relationship connection.

\section{UPGRADING PATH DESIGN OF REGIONAL EQUIPMENT MANUFACTURING INDUSTRY}

In order to promote the industrial upgrading of regional equipment manufacturing industry, the path design should follow scientific principles, systematic principles and operational principles. Designing the upgrading path of regional equipment manufacturing industry is not only for academic research, but also for practical application, so it must be operable. The path should be designed in combination with industrial development, subject status, regional status and other factors. It is necessary to consider the feasibility of collaborative innovation activities among subjects and the innovation ability of the whole system, as well as the 
integration of across organizations, equipment manufacturing sub-industries and supporting industries.

Based on the above design principles, this paper starts with the core layer, supporting layer and supporting layer to establish an upgrading and transformation path from inside to outside, from point to line and then to surface, focusing on the design of upgrading paths based on key common industrial technologies, supporting industrial chain optimization and industrial innovation platform. The specific ideas are as follows: the industrial upgrading path should meet the needs of different development stages of regional equipment manufacturing industry. The development stages and priorities of equipment manufacturing industry in different regions of China are different, so it is necessary to combine the characteristics and needs of each stage of industrial development to design the upgrading process of equipment manufacturing industry of mutual connection, dynamic adjustment and spiral rise.

\section{A.Upgrading Path Based on Industrial Key Common Technologies}

The upgrading path based on industry key common technologies is to realize the technological innovation and upgrading of regional equipment manufacturing industry with the breakthrough innovation of key common technologies [10], laying the technical foundation of industrial upgrading from the root, and promote the improvement of the structure and quality of regional equipment manufacturing industry. The specific upgrading path is shown in Fig. 1. Through collaborative innovation modes such as R\&D alliance, industry-university-research alliance in the innovation network of equipment manufacturing industry, the key common technology innovation can be realized by integrating network innovation elements, then realizing the popularization and application of key common technologies through network sharing mechanism, and gradually infiltrating into relevant fields or links of regional equipment manufacturing industry, thus enhancing the core competitiveness of regional equipment manufacturing industry and gradually realizing the upgrading of elements, value chain and structure of regional equipment manufacturing industry.

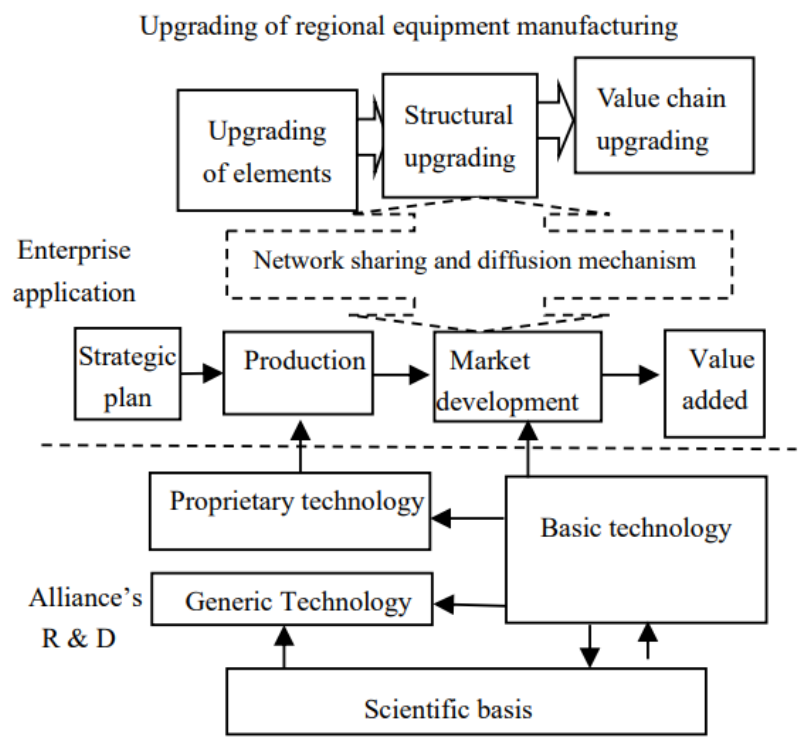

Figure 1 The upgrading path based on industrial key-generic technology

The upgrading path based on industry key common technology is based on the long-term stable cooperation of "government-industry-university-scientific research institution-enterprise", so this path is applicable to:

1) The regional equipment manufacturing industry has a certain industrial base, and the government strongly supports and guides the key common technological innovation and gives policy and financial support. At the same time, enterprises with technological advantages can promote the diffusion of technology in the industry.

2) The regional equipment manufacturing industry is caught in the bottleneck of technological innovation or has been focusing on technology introduction, striving for technological breakthrough and independent innovation.

3) The overall strength of equipment manufacturing enterprises in the region is relatively average, and there are no outstanding equipment manufacturing enterprises, and production technology and product development mostly rely on imitation innovation or introduction of technological innovation.

\section{B.Upgrading Path Based on Supporting Industrial Chain Optimization}

The upgrading path of equipment manufacturing industry based on the optimization of supporting industrial chain is to concentrate resources to give full play to the industrial advantages of equipment manufacturing industry, make it present considerable development prospects, attracting upstream and downstream enterprises to integrate into the equipment manufacturing industry chain, forming an equipment manufacturing cluster centered on core manufacturing enterprises. It can realize collective mutual learning, resource sharing and capability complementarity through the dynamic integration of competition and cooperation within the cluster, and enhance the overall independent innovation capability, and promote the innovation activities and upgrading of equipment manufacturing industry, as shown in Fig. 2. 


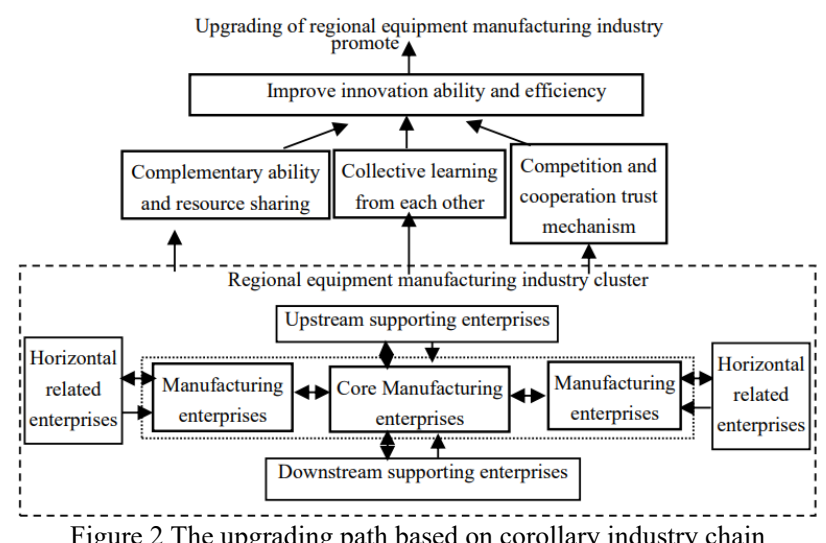

Figure 2 The upgrading path based on corollary industry chain optimization

The conditions of endogenous upgrading path based on supporting industrial chain optimization are as follows:

1) This path requires that there are a certain number of core enterprises with strong comprehensive strength in the region, which can attract many supporting enterprises to provide corresponding technologies or products.

2) This path has higher requirements for supporting enterprises, and requires them to cooperate with the develop-ment needs of equipment manufacturing enterprises with core key technologies or development potential, and constantly cultivate their own core advantages with the times to become an important support for the development of auxiliary equipment manufacturing enterprises.

\section{Upgrading Path Based on Industrial Innovation Platform}

Industrial innovation platform is a comprehensive integrated carrier that provides innovative resources such as information, technology and manpower for all innovative subjects in the region, and reasonably guides industrial upgrading, and integrates functions and services such as technological product research and development, achievement transformation, technical services, scientific and technological venture investment services, and personnel training [11]. It is a network with multiple subplatforms and enterprises, universities, scientific research institutions, government, financial and intermediary service institutions as network nodes, which generates various interactive relationships through corresponding implementation mechanisms, and achieves the effective collection, integration, allocation and re-innovation of innovative resources such as human, financial, material, information and technology among each node [12]. The upgrading path based on industrial innovation platform is a gradual upgrading process, which takes the construction of industrial innovation platform as the cornerstone of innovation and upgrading of regional equipment manufacturing industry, and regard the innovation subject as the network node to build network relations, to enhance the innovation ability of enterprises and industries, as shown in Fig. 3.

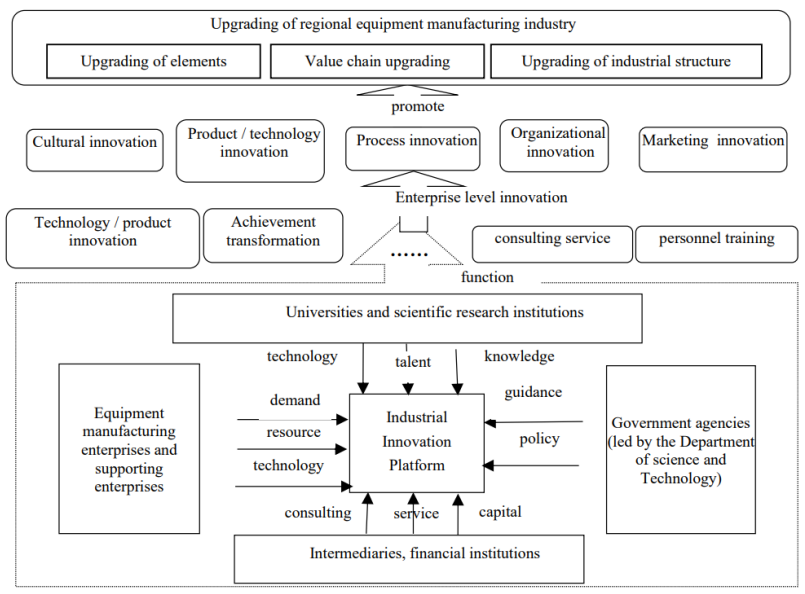

Figure3 The upgrading path based on the industry innovation platform

The path of industrial upgrading based on innovation platform is applicable to the following situations:

1) This path is suitable for the regional equipment manufacturing industry, which has a relatively strong industrial base, grasps the core resources and seeks breakthroughs, or has potential for development. At the same time, the regional scientific and technological resources are relatively rich, and the innovation activities are relatively active.

2) Because the short-term profit of the initial industrial innovation platform will not be ideal, it needs the strong support of the government and industrial alliance, as well as the core manufacturing enterprises with strong scale and strength and R\&D institutions with strong scientific research ability will continue to participate.

3) This path is suitable for the innovation network of regional equipment manufacturing industry in the growth and maturity stage. Core enterprises strive to seek new development breakthroughs. At the same time, regional governments are required to attach great importance to the development of regional equipment manufacturing industry, and actively introduce new innovation subjects needed in the network, and constantly enrich the types and quality of innovation resources.

\section{CONCLUSIONS AND COUNTERMEASURES}

The upgrading path of regional equipment manufacturing industry is designed with reference to the innovation network structure and evolution process of equipment manufacturing industry, industrial development level and other factors. The upgrading path based on key common technological innovation breakthrough, supporting industrial chain development and innovation platform needs continuous improvement and practice to ensure the innovation and upgrading of regional equipment manufacturing industry. Therefore, this paper puts forward the following countermeasures and suggestions:

1) Improving the functional convergence among all innovation subjects. Innovation and upgrading of regional equipment manufacturing industry is a long-term and complex process, which requires efficient cooperation among innovation subjects to improve the efficiency of innovation activities and the conversion rate of innovation achievements. At the same time, it requires further 
clarification of the division of labor and responsibilities among innovation subjects, establishment of trust mechanism and coordination mechanism, and realization of functional complementarity and convergence.

2) Strengthening government guidance and services. The upgrading of regional equipment manufacturing industry requires the government to formulate and implement numerous policies to stimulate the innovation desire of innovation subjects. The challenge and mission of upgrading regional equipment manufacturing industry not only requires manufacturing enterprises to seek upgrading opportunities in combination with the current situation, but also requires the government to create development opportunities, guiding all innovation subjects to establish connections and creating a good environment for upgrading.

3) Cultivating key technologies to realize breakthrough and innovation. Firstly, manufacturing enterprises need to enhance the independent innovation ability through alliance innovation and accelerate the research and development of key technologies; Secondly, they must choose key technologies to ensure that this technology really has cutting-edge performance to drive and promote the development of equipment manufacturing industry; Finally, strengthening international cooperation, encouraging qualified enterprises to participate in the international division of labor and cooperation of equipment manufacturing industry with a wider scope and higher level, and establishing technical alliances with foreign enterprises, then they can achieve complementary advantages and winwin development.

4) Strengthening the matching between regional innovation resources and upgrading needs. Regional equipment manufacturing industry is affected by regional culture, economic environment and other factors. When seeking upgrading opportunities, it is necessary to consider the matching degree of regional resources to rationally optimize the allocation of resources and realize innovation with regional characteristics, or developing and introducing new resources to meet the upgrading needs of regional equipment manufacturing industry.

\section{ACKNOWLEDGMENT}

This research was supported by the National Natural Science Foundation of China (No. 71704036); Philosophy and Social Sciences Research Planning Project of
Heilongjiang Province (No. 20GLB119) ; "13th FiveYear Plan" Key Project of Education Science of Heilongjiang province (No. GBB1318051) ; Outstanding Young Talent Project of Talents Plan of Harbin University of Science and Technology (No. 2019KYYWF-0216).

\section{REFERENCES}

[1] Tang Xiaoyun. A summary of industrial upgrading research [j]. Scientific and Technological Progress and Countermeasures, 2012,29 (4): 157-160.

[2] GEREFFI G. International trade and industrial upgrading in the apparel commodity chain[J].Journal of International Economics, 1999, (48):37-70.

[3] POON T, SHUK CHING. Beyond the global production works: a case of further updating of Taiwan's information technology industry[J]. International Journal of Technology and Globalisation,2004,1(1):130-144.

[4] MASAMI ISHIDA, TOMOHIRO MACHIKITA, Yasushi Ueki. How export and import platforms drive industry upgrading: five facts about emerging multinationals from southeast Asia[J]. Asian Journal of Technology Innovation,2013,21(1):4-24.

[5] LI Weiqing. Information industry upgrading sensing technology using plasmatic waveguide directly coupled to rectangular cavity[J] Sensors \& Transducers,2013,160(12):503-508.

[6] Zeng Gui, Zhong Jian. Discussion on the transformation and upgrading of processing trade in global production network [J]. Soft Science, 2011, 25 (2): 62-66

[7] Tu ying-Qing, Chen Wen, problems and paths of upgrading China's automobile industry [J], enterprise economy, 2011, (6): 109-111.

[8] Qian Fangming, Research on Upgrading Mechanism of Traditional Manufacturing Industry in Yangtze River Delta Based on NVC [J], Scientific Research Management, 2013,34 (4): 74-78.

[9] Wang Haijie, Wu Ying, Research on the Path of Industrial Upgrading in Underdeveloped Areas Based on Regional Value Chain [J], Economic System Reform, 2014, (4) : 38-42.

[10] Ma Yonghong, Kong Lingkai, Lin Chaoran, Yang Xiaomeng. Research on identification of key generic technologies based on patent mining [J]. Journal of Information Technology, 2020,39 (10) 1093-1103

[11] Xia Houxue, Tan Qingmei, Wang Bin. Research on new industrial innovation platform for high-end equipment manufacturing industry from the perspective of intelligent production and service network [J]. Scientific Research Management, 2017, 38 (12): 1-10

[12] Wang Xueyuan and Wang Hongqi. Research on the Relationship among Network Characteristics, Service Effect and Enterprise Innovation Performance of Regional Innovation Platform [J]. Science and Management of Science and Technology, 2013,34 (5): $80-88$. 